\title{
COLLECTION AND ANALYSIS OF RADIAL-GROWTH DATA FROM TREES FOR EVIDENCE OF PAST SPRUCE BUDWORM OUTBREAKS ${ }^{1}$
}

\author{
By J. R. BLAIS ${ }^{2}$
}

\begin{abstract}
Methods used in the collection of radial-growth data from host and nonhost trees of the spruce budworm for the purpose of establishing evidence of past spruce budworm outbreaks are described. The preparation and examination of the material and the interpretation of the data are discussed. These techniques are based on experience gained in the course of studies in three widely-separated regions in Ontario and Quebec over a period of several years.
\end{abstract}

\section{INTRODUCTION}

In recent years radial-growth data were obtained by the author from over 2,000 trees in Ontario and Quebec in an effort to gain information on past outbreaks of the spruce budworm, Choristoneura fumiferana Clem. The main object was to establish the time of occurrence of past outbreaks and to determine their geographical extent, intensity, and duration through analysis of reductions in radial-growth in the host trees. Results of investigations carried out in northwestern Ontario and in the lower St. Lawrence and Gaspé regions of Quebec have been published $(1,5)$, while findings from the Laurentide Park region of Quebec are yet to be published. In the course of this work a considerable amount of experience was gained in the collection and interpretation of radial-growth data from host and non-host trees of the spruce budworm. Although the methods used apply more specifically to studies on past spruce budworm outbreaks, some of the experience gained might be useful in the study of past outbreaks of any tree defoliator in the temperate zone, through ring-growth studies of the host trees.

\section{COllection of Material}

The main hosts of the spruce budworm in eastern North America are balsam fir, Abies balsamea (L.) Mill., white spruce, Picea glauca (Moench) Voss, and black spruce, Picea mariana (Mill.) BSP. Red spruce, Picea rubens Sarg., is also attacked by the insect but this species has a limited distribution. Although balsam fir is the most susceptible host and defoliation by spruce budworm is most clearly reflected in the radial growth of this species, it is not as long-lived as the spruces, and, because of the great vulnerability of balsam fir to spruce budworm attack, many mature trees are destroyed at the time of outbreaks, thus reducing the number of old trees of this species in the forest. Consequently, balsam fir generally cannot be used to obtain information on outbreaks that occurred more than 75 years previously. White spruce trees, however, can provide excellent records over

\footnotetext{
${ }^{2}$ Contribution No. 901, Forest Entomology and Pathology Branch, Department of Forestry, Ottawa, Canada.

- Forest Research Laboratory, P.O. Box 35, Sillery, Quebec. Biographical reference For. Chron. 33.
} 
long-term periods. This species, although less susceptible to attack by the budworm, does suffer severe defoliation with resulting radial-growth suppression. Because it is long-lived, it is possible to find trees 150 to 200 years old, and rarely, trees over 300 years old. Black spruce is more resistent to budworm attack than the other two species (2), and is less likely to reveal the occurrence of past budworm infestations. However, it is long-lived, and can sometimes furnish information on past outbreaks in localities where no old balsam fir or white spruce trees occur.

Radial-growth reductions caused by severe spruce budworm infestations are usually readily recognized (Fig. 1). In cases where outbreaks are less severe, the resulting moderate growth reduction is often difficult to distinguish from random or weather-induced fluctuations. Therefore, in order to ascertain that certain growth reductions are attributable to budworm defoliation, it becomes necessay to compare radial growth in host trees with that in non-host trees. White pine, Pinus strobus L., and red pine, Pinus resinosa Ait., have proved to be best suited for this purpose. Both species are longlived, and although they are not common, they occur throughout most of the area where spruce and fir are attacked by the budworm. Because the pines usually grow on mesic or xeric sites, they respond to climate in a manner more similar to spruce and fir than coniferous species growing on hydric sites.

Radial-growth data for all trees were obtained from increment cores or from cross-sectional discs cut from the stems. Discs are much preferable to cores, but under certain circumstances only the latter can be obtained.

When borings were obtained, three cores were taken from each of ten trees of the same species, for each locality. The cores were taken at breast height along trisecting radii. Each core was marked with an indelible pencil as to tree number and core number. The cores for each tree were sealed in separate paper envelopes.

Cross-sectional discs were usually taken from each of five trees of a given species for each locality sampled. Discs were obtained from three sources: standing trees at breast height, stumps of recently felled trees, and logs. Before felling a tree, an increment core was usually taken to check the age and the growth pattern. Old trees devoid of rot and having uniform growth were more often found on medium to poor sites.

The three species of host trees often showed pronounced radial-growth suppression as a result of shading for more or less prolonged periods of time during the earlier years of growth. Any reduction in radial growth that might have been caused by budworm defoliation during periods of intense shading were undetectable, and only the growth patterns after release from shading could be used. Sometimes, growth was suppressed toward the periphery of the trunk; this is usually due to a slowing down of the growth process as a result of age. For instance, peripheral radial-growth suppression in mature jack pine, Pinus banksiana Lamb., trees is characteristic of this species, and for this reason it could not be used as a control. When more precise information on recent infestations was required, discs were obtained from the upper trunk as well, because radial growth in this region of the stem is more sensitive to defoliation (7). 
It was preferable however to obtain discs from stumps of recently felled trees or from logs since a cross section of the growth rings was clearly visible at a glance. Many hundreds of stumps and stacked logs could be examined in a short time, and desirable specimens could be quickly selected. Stumps, especially if cut very low, sometimes showed a distortion in radial growth owing to butt flare. For this reason logs were a better source of material, and sometimes, because of butt flare, discs were cut from the small end of butt logs. When using material from stumps or logs it was useful to know when cutting took place. However, even when this was not known, the last year of growth could usually be established by using the techniques described below. The origin of sample logs was readily established when they were still in the forest near the cutting sites. When logs were in mill yards, their point of origin was established through the owner of the mill.

In the course of a season several hundred discs were accumulated. Moulds were not a serious problem when discs were piled in a well aerated room In a staggered fashion so as to allow free passage of air between them.

\section{Preparation and Examination of the Material and Interpretation OF THE DATA}

Increment cores and discs were examined with a binocular microscope equipped with an ocular micrometer. Ring-width measurements were made at a magnification of 8 , although higher magnifications were used to detect the presence of very, narrow rings.

Increment cores were placed in a specially designed holder (Fig. 3) and sliced longitudinally with a sharp knife to expose a fresh-cut surface. Before examination under microscope the core wasl m.oistened with water to accentuate the difference between spring and summer wood. Rings were counted starting with the outermost one. An indelible pencil was used to dot each ring and to mark every tenth one with a dash. Rings were then measured and their widths properly recorded.

Before examination, the discs were polished on one face with a sanding machine to highlight the growth pattern. Rings were counted and measured along three radii on each disc at angles approximately 120 degrees (Fig. 2). The same procedure for marking and measuring the rings was followed as for the increment cores. Some of the discs were examined by sliding a binocular microscope with a regular base along the surface of the disc, but the task was made easier when the microscope was mounted on a universal table stand especially designed to work on large opaque objects. The surface of the disc was moistened along the radii being examined by applying glycerine with a small brush. Individual rings thus stood out clearly. Moistening with water produced the same effect, but water dried quickly and had to be re-applied in the course of the examination, while glycerine remained effective for a long time. Where the surface of the disc was roughened or where the rings were very narrow, it was necessary to cut a shallow V-shape groove with a sharp knife along part of the length of the radius being examined in order to expose a perfectly smooth surface.

While one person could measure and record ring widths, the addition of a recorder resulted in quicker and more accurate work. 
In the case of discs, it was important that measurements for each of the three radii be synchronous for each disc. This was readily achieved by following one or more rings through the three radii. For instance when the ring produced 100 years earlier for radius $A$ was also 100 years old in radii $B$ and $C$, then the counts for the three radii were assumed correct to that point. It followed that the last ring to be checked in this fashion should be near tho centre of the disc.

Characteristic narrow or wide rings were representative of certain calendar years in all samples examined for the different study areas. For instance, the 1876 ring was very narrow in all trees studied in the Laurentide Park region of Quebec, but the 1931 ring was unusually wide; in the Gaspé Peninsula aarrow rings were formed in 1890 and 1909 , and a wide ring occurred in 1910; in northwestern Ontario a narrow ring was produced in 1857. These key rings were most useful in confirming the correct dating of the growth rings. Rings from individual trees were considered to be dated correctly when key rings from these trees were in phase with those established for the region. In certain cases where difficulty was experienced in correctly dating the rings of a tree, a graph depicting the growth profile of that tree was superimposed on the graph of the average growth for trees of the same species from the same area. A light table was used for this purpose. It was usually very apparent when the growth profile of the tree being tested fell in phase with the average radial growth. This method made possible the correct dating of material recovered from logs or from dead trees where the last year of growth was unknown.

When all measurements were completed, the average yearly radial growth for each locality for each budworm host-tree species, and the average yearly radial growth for all localities for non-budworm-host trees was calculated. This pooling of the data tended to eliminate minor radial-growth fluctuations from tree to tree, and to accentuate fluctuations common to a locality or a region. The results were plotted on large sheets of graph paper, and the growth profiles of the pooled data quickly revealed the presence of any common radial-growth suppression. In the case of outbreaks that occurred more than 150 years ago, data could be obtained only from a few old trees scattered over the whole region, and such data were also combined,

Before compiling the average growth for all trees from one or several localities, the yearly radial-growth measurements from each tree were examined. Any period showing an outstanding alteration in growth specific to an individual tree was eliminated from the calculations. For instance, rings formed near the pith are usually very large in open-grown trees. This is true for all levels of the trunk and is the result of a normal physiological process (6). When even-aged trees are studied, these rings can be included in the average growth pattern for a given species from a given locality; the wide rings produced during the earlier years then become a regular feature of the growth profile. However, when the average yearly radial growth is calculated for uneven-aged trees, as was the case in the present studies, the time of occurrence of the wide rings near the pith varies between trees, and their inclusion will distort the average growth pattern. Very narrow rings formed 
as a result of intense shading during part of the growing period (usually at the heart of the stem) or as a result of declining vigour (toward the periphery of the stem) were also eliminated from the average yearly radial-growth calculations.

Aside from these more or less prolonged periods of suppression due to competition and occasionally to old age, radial growth in white spruce and balsam fir is relatively uniform. Drastic growth fluctuations such as found in larch, Larix laricina (Du Roi) K. Koch, (8) do not occur in these two tree species although such fluctuations are sometimes found in black spruce. The presence of a series of narrow rings occurring amongst rings of regular growth is unusual and therefore very noticeable. Radial-growth suppression caused by spruce budworm defoliation is characterized by a series of rings of decreasing size followed by rings of gradually increasing width (Figs. 1 and 4). At times of severe defoliation, the ring of greatest suppression is usually very narrow and sometimes only a discontinuous or partial ring is formed. Weather could be eliminated as a possible cause of suppression when radial growth was noticeably reduced in the host trees but not in the pines. Although a number of other defoliators occasionally cause severe defoliation of white spruce or balsam fir, a spruce budworm outbreak is the only known factor that can cause a ring-growth suppression specific to both balsam fir and white spruce trees over extensive areas (5).

The number of suppressed rings and the degree of suppression is dependent on the duration and intensity of an outbreak. In the samples studied in Quebec, growth suppression attributable to spruce budworm defoliation was classified as being either light or severe. This was determined by comparing the width of the ring of greatest reduction with the average radial growth for the decade preceding the outbreak. When the width of the ring of greatest suppression was not more than one-half the average for the decade, the trees were considered as having suffered severe suppression; when it was greater than one half but less than the average for the decade, the trees were considered as exhibiting light suppression. Studies of a current outbreak have shown that an average reduction in radial growth of 50 per cent was usually associated with incipient mortality amongst the most vulnerable trees $(3,4)$. Therefore it is probable that some tree mortality occurred during past infestations where the average radial growth was reduced by 50 per cent or more.

The degree of radial-growth reduction suffered at the time of a budworm infestation is not necessarily the same for all trees from a given locality. Young and vigorous white spruce and balsam fir trees are less subject to budworm damage than mature trees of low vigour (4). Therefore, because of their high vigour at the time of past outbreaks, some of the trees sampled could exhibit a light suppression although in fact the infestation was severe. The condition of the growth rings immediately preceding and following the growth decline reveals the growing conditions of the tree at that time. If the tree was producing wide rings, it was of high vigour, and any surrounding trees that were of poorer vigour most probably suffered more severely.

Although the severity of past outbreaks can be ascertained from the degree of radial-growth suppression, the beginning and the duration of past 
outbreaks cannot be dated exactly. Radial-growth suppression in white spruce and balsam fir does not coincide with defoliation. At breast height, it starts two to four years after the first year of severe defoliation and continues for some years after defoliation has stopped (3). Trees of high vigour that have suffered light or moderate defoliation will recover quickly, while in trees of poor vigour that have been severely defoliated, normal growth may be resumed only many years after the outbreak has ceased. Because growth in the upper stem is somewhat more sensitive to defoliation than growth in the lower stem, data from the upper stem reflect more exactly the time and degree of defoliation. However, since only the last years of growth are found in the upper stem, these data can only supply information for outbreaks that have occurred in the last 20 years. It is possible to locate the region of the upper stem at the time of outbreaks that occurred long ago by sectioning the stem. However, this is a tedious task that can hardly be undertaken when a large number of samples from a widespread area are desired. Furthermore, this type of information can be obtained only from trees felled for the purpose, and increment cores or discs from logs or stumps constitute the most practical source of data for studies on old outbreaks.

In addition to revealing the intensity of past infestations, radial-growth data can sometimes furnish other information. For instance, in the case of the most recent outbreak that occurred in the Laurentide Park region of Quebec it was possible to determine that in a large sector of this 10,000-squaremile area, populations of the insect reached two peaks during the outbreak period. Radial growth was reduced as a result of a first wave of defoliation, and, following partial recovery after this first attack, growth was again severely suppressed indicating that insect populations increased to a second peak 2 to 3 years later (Fig. 5). The resurgence of spruce budworm populations after a marked decline over widespread areas has seldom been observed and evidence of such occurrence is of considerable interest.

\section{CONCLUSIONS}

By using the techniques described above, it has been possible to determine the time of occurrence, the geographical extent, the intensity and duration of past spruce budworm infestations for the Lac Seul area of northwestern Ontario, the Gaspé and St. Lawrence regions, and the Laurentide Park region of Quebec. The information covers the past century for the two first regions, and the past 300 years for the last region where evidence was found of five successive outbreaks between 1670 an 1960. There are many other regions in eastern North America where few or no data are available on past spruce budworm infestations. This type of information would be most useful in understanding the frequency of recurrence of these outbreaks and in making predictions for the future. 


\section{REFERENCES}

1. BLAIS, J. R. 1954. The recurrence of spruce budworm infestations in the past century in the Lac Seul area of northwestern Ontario. Ecology 35:62-71.

2. BLAIS, J. R. 1957. Some relationships of the spruce budworm to black spruce. For. Chron. $33: 364-372$.

3. BLAIS. J. R. 1958. Effects of defoliation by spruce budworm on radial growth at breast height of balsam fir and white spruce. For. Chron. 34:39-47.

4. BLAIS, J. R. 1958. The vulnerability of balsam fir to budworm attack in northero Ontario, with special reference to the physiological age of the tree. For. Chron. 34:405-422.

5. BLAIS, J. R. 1961. Spruce budworm outbreaks in the Lower St. Lawrence and Gaspé regiors. For. Chron. 37:192-202.

6. DUFF, G. H. and N. J. NOLAN. 1953. Growth and morphogenesis in the Canadian forest species. 1. The controls of cambial and apical activity in Pinus resinosa Ait. Can. J. Bot. $31: 471-513$.

7. MOTT, D. G., L. D. NAIRN, and J. A. COOK. 1957. Radial growth in forest trees and effects of insect defoliation. For. Sci. 3:286-304.

8. NAIRN, L. D., W. A. REEKS, F. E. WEBB, and V. HILDAHL. 1962. History of larch sawfly outbreaks and their effect on tamarack stands in Manitoba and Saskatchewan. Can. Ent. 94:242-255.

Figures 1-5 are on pages 481-484. 


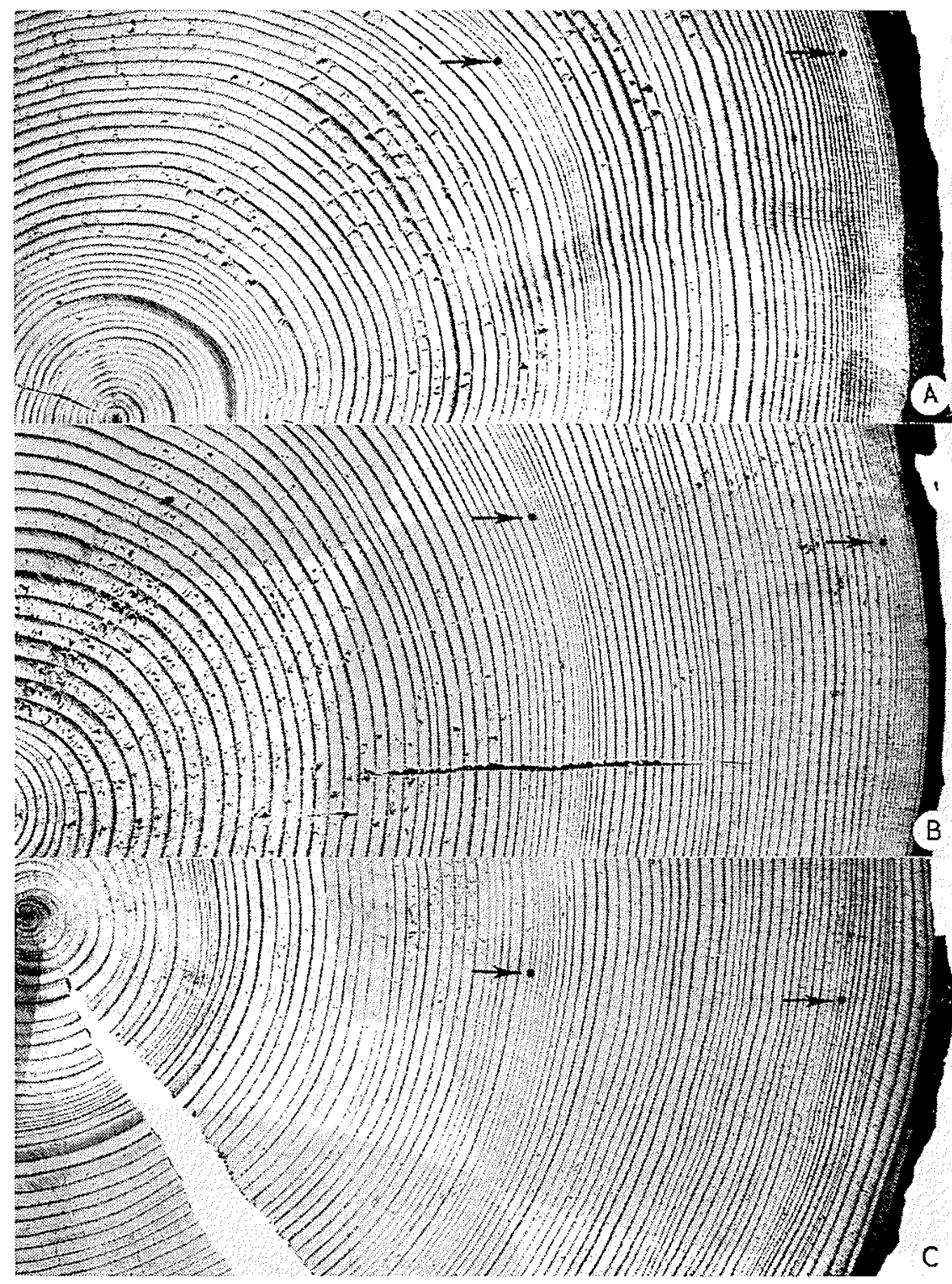

FIGURE 1. Portions of basal discs from: (A) balsam fir; (B) white sprucc; (C) black spruce from Tourilli Lake in the Laurentide Park of Quebec, showing cvidence of spruce budworm infestations starting about 1913 and about 1950. 


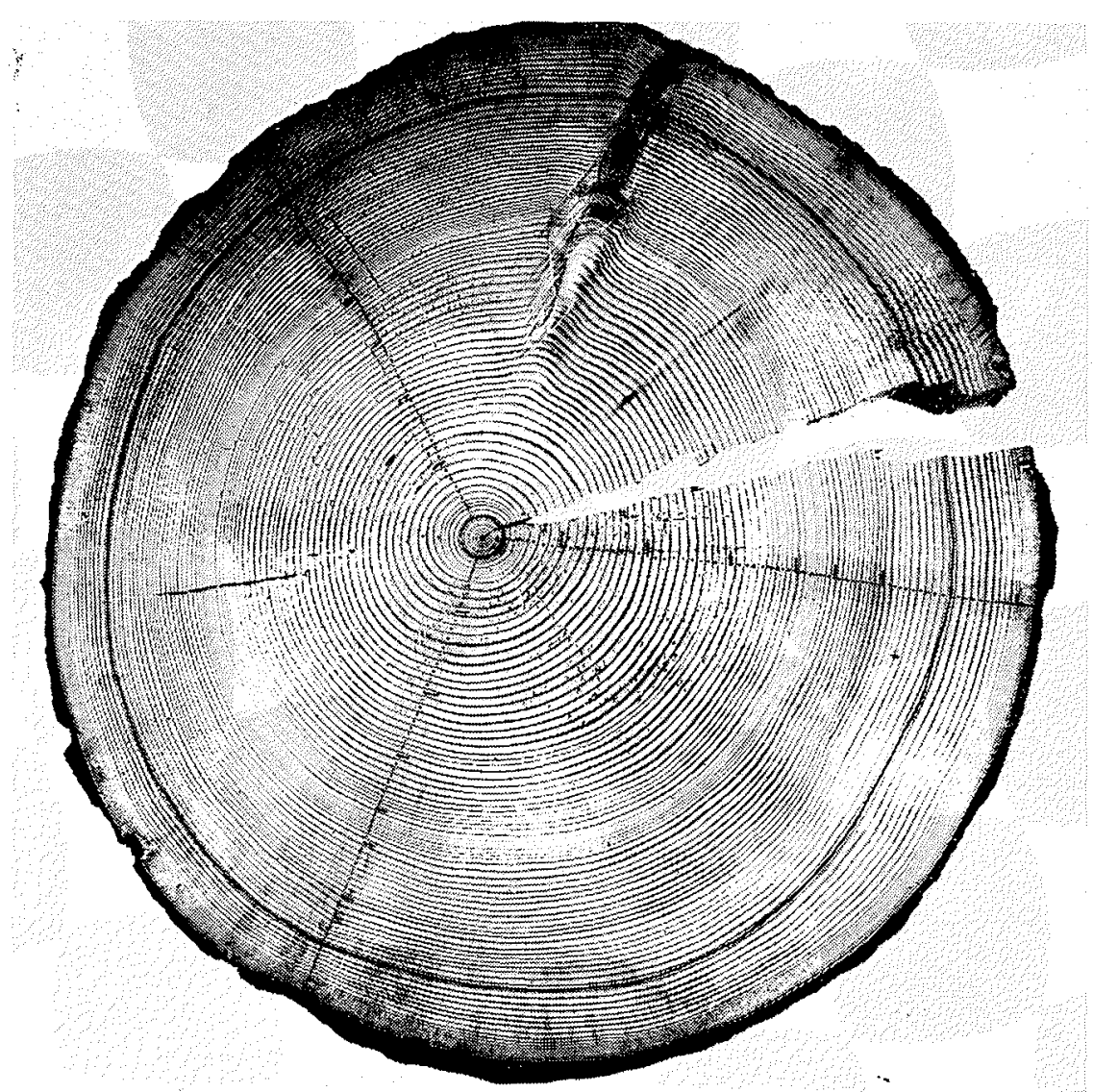

FIGURE 2. Basal disc from white spruce trec made ready for yearly radial growth measurements along three radii.

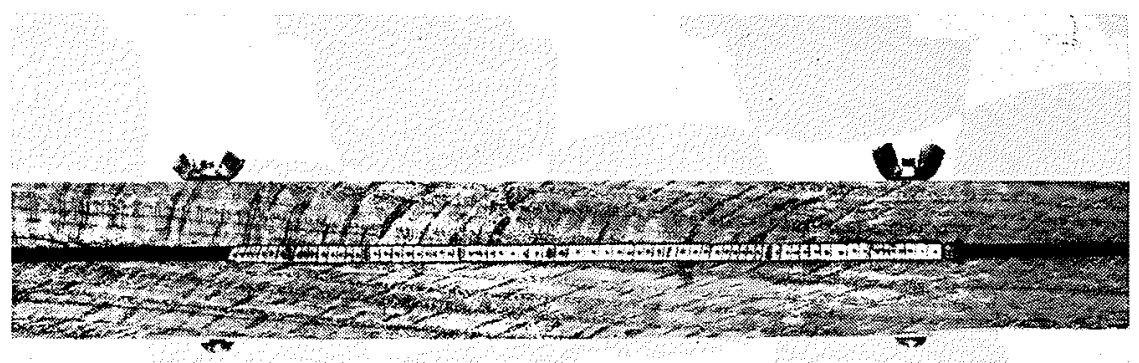

FIGURE 3. Increment core from a white spruce tree held in a specially-designed holder and made ready for ring-growth measurements. 


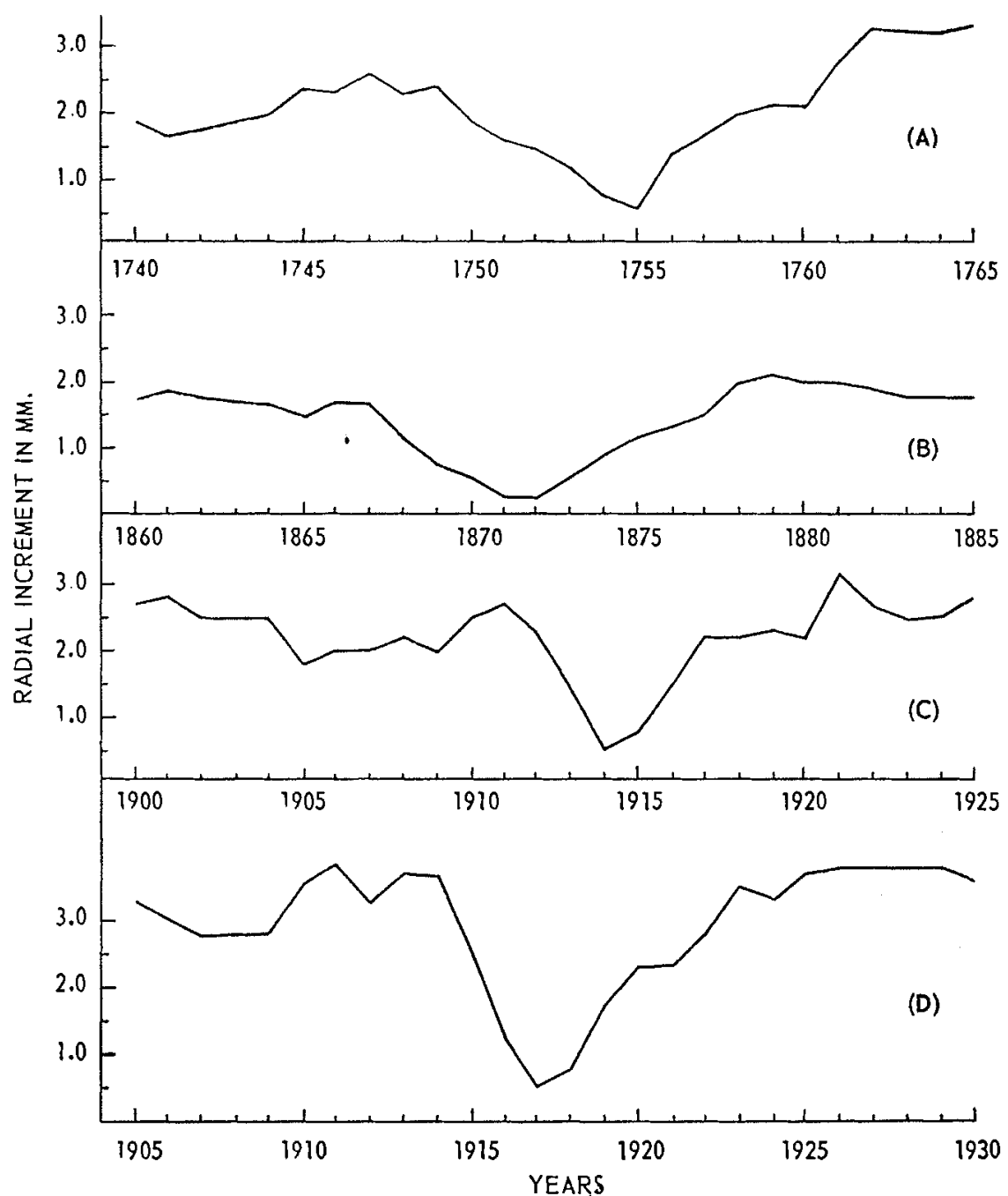

FIGURE 4. Average yearly radial growth for a number of white spruce and balsam fir trees showing severe suppression for part of various 25 -year growing periods as a result of past spruce budworm outbreaks in different regions of Ontario and Quebec: (A) average radial growth from 1740 to 1765 based on cross sectional basal discs from 8 white spruce trees from 4 different localities in the Laurentide Park, Quebec, showing evidence of an outbreak beginning about 1750 ; (B) average radial growth from 1860 to 1885 based on increment cores from 10 white spruce trees from Basket Lake in northwestern Ontario, showing evidence of an outbreak beginning about 1886; (C) average radial growth from 1900 to 1925 from basal discs of 5 balsam fir trees from Stoneham in central Quebec, showing evidence of an outbreak beginning about 1913; (D) average radial growth from basal discs of 5 balsam fir trees from Metis Lake in eastern Quebec, showing evidence of an outbreak beginning about 1915 . 


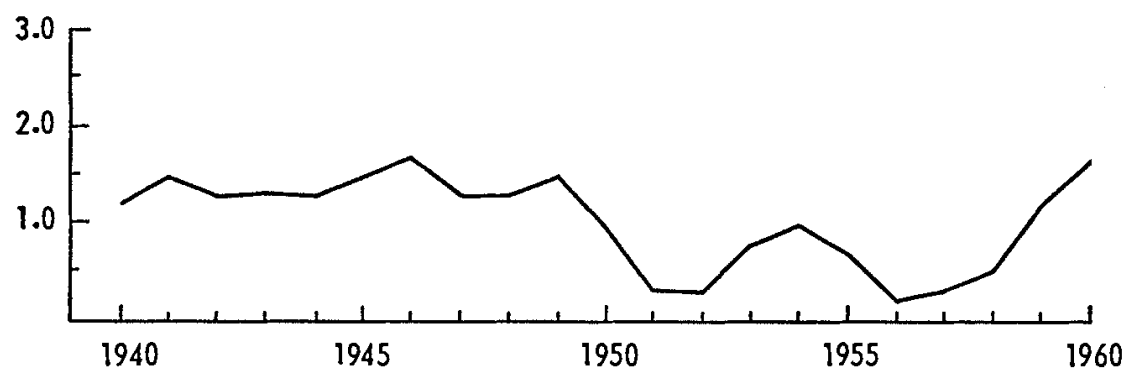

FIGURE 5. Average radial-growth measurements from 1940 to 1960 for 5 balsam fir trees from Bailloquet Lake in Quebec showing two successive suppression periods, the result of two waves of defoliation at the time of a recent spruce budworm outbreak in central Quebec. 